TID-4500, UC- 35

Nuclear Explosions-

Peaceful Applications

Iawromoo IRadiation Laboxatoxy

UNIVERSITY OF CALIFORNIA

IIVERMORE

\title{
UCRL-50519 \\ THEORETICAL AND EXPERIMENTAL STUDIES RELATING TO THE PURGING OF RADIOACTIVITY EROM A GAS WELL STIMULATED BY A NUCLEAR EXPLOSION
}

G. H. Higgins

D. D. Rabb

H. C. Rodean

December 24, 1968

\section{IEG AL NOTICE}

This report was prepared as an account of Government sponsored work. Neither the United States, nor the Commission, nor any person acting on behalf of the Commission:

A. Makes any warranty or representation, expressed or implied, with respect to the accuracy, completeness, or usefulness of the information contained in this report, or that the use of any information, apparatus, method, or process disclosed in this report may not infringe

vately owned rights; or

B. Assumes any liabllities with respect to the use of, or for damages resulting from the use of any Information, apparatus, method, or process disclosed in this report.

As used in the above, "person acting on behalf of the Commission" includes any employee or contractor of the Commistion, or employee of such contractor, to the extent that such employee or contractor of the Commission, or employee of such contractor prepares, disseminates, or provides access to, any information pursuant to his employment or contract with the Commission, or his employment with such contractor.

This document is

PUBLICLY RELEASABLE BSteelo

Authorizing Official

Date: $\quad 316 \cdot 07$ 


\section{DISCLAIMER}

This report was prepared as an account of work sponsored by an agency of the United States Government. Neither the United States Government nor any agency Thereof, nor any of their employees, makes any warranty, express or implied, or assumes any legal liability or responsibility for the accuracy, completeness, or usefulness of any information, apparatus, product, or process disclosed, or represents that its use would not infringe privately owned rights. Reference herein to any specific commercial product, process, or service by trade name, trademark, manufacturer, or otherwise does not necessarily constitute or imply its endorsement, recommendation, or favoring by the United States Government or any agency thereof. The views and opinions of authors expressed herein do not necessarily state or reflect those of the United States Government or any agency thereof. 


\section{DISCLAIMER}

Portions of this document may be illegible in electronic image products. Images are produced from the best available original document. 


\section{Contents}

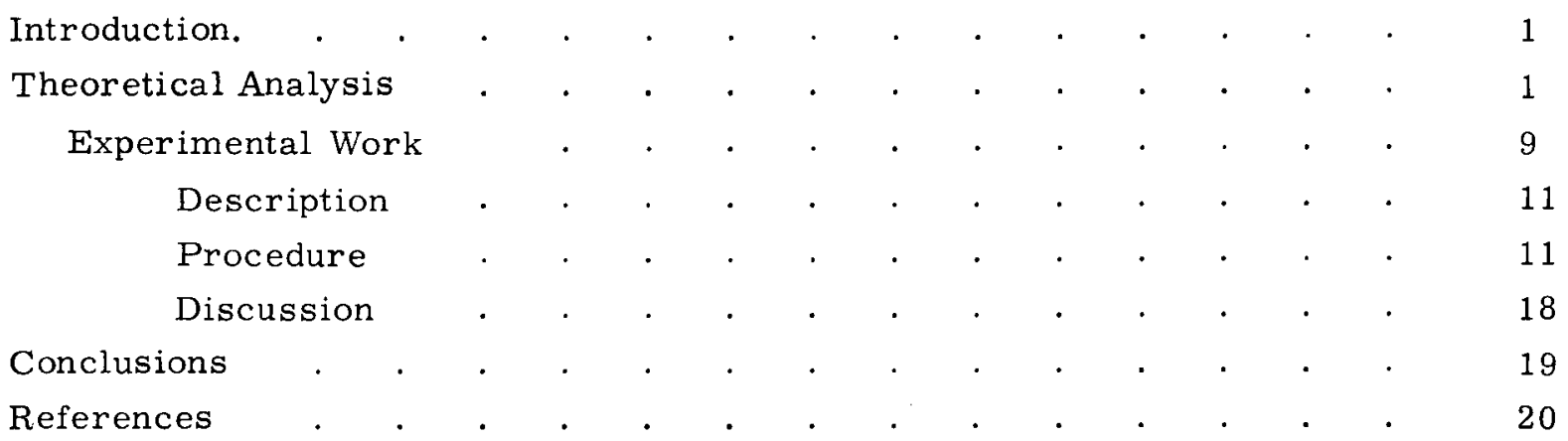




\title{
THEORETICAL AND EXPERIMENTAL STUDIES RELATING TO THE PURGING OF RADIOACTIVITY FROM A GAS WELL STIMULATED BY A NUCLEAR EXPLOSION
}

\author{
Introduction
}

One question associated with the use of nuclear explosions for natural gas well stimulation is that of eliminating or controlling the radioactivity in the gas produced from the well. A proposed solution is to purge the chimney ${ }^{*}$ before permitting the gas to enter the pipeline, and to phase-in the production of the well so as to obtain a dilution of activity to an acceptable level. The variation in the radioactivity concentration during a purge is pertinent to the problem. A previous analysis ${ }^{1}$ was reviewed and it was determined that further study on this problem was necessary. After being revised and extended, the resultant estimated variation of radioactivity concentrations during well production for a range of chimney geometries was prepared and compared with uniform mixing models. The revised analysis indicates that the quantity of gas which may be flared to remove substantially all the radioactivities may be only about one-half that previously estimated.

The classic uniform mixing model used to evaluate mixing in a large tank of constant in-and-out flow leads to continuous exponential decrease in radioactivity concentration which approaches but never reaches zero. The displacement model presented here leads to a small volume of release at constant concentration followed by a rapid decrease, finally going to zero in two to four chimney volumes. The concentration deduced from the displacement model is initially higher but at late times less than that deduced from the constant mixing model. Experimental tests of both models are discussed.

\section{Theoretical Analysis}

First, assume a nuclear chimney in the idealized form of a vertical, right circular cylinder with radius, $R$, and height, $H$. Also assume that this chimney is located in a natural gas reservoir, and that the top and bottom chimney surfaces coincide with the top and bottom of the reservoir. The reservoir may be of infinite

\footnotetext{
"For a description of the nuclear "chimney" and other features produced by underground nuclear explosions, see UCRL-14756, "Industrial Applications of Contained Nuclear Explosions," D. E. Rawson, July 1966.
} 
horizontal extent, or it may be finite, in the form of a right circular cylinder with a radius much greater than the chimney radius, $R$. The top and bottom surfaces of the chimney and reservoir are impermeable except for a non-penetrating drainage well located at the top center of the chimney. The chimney properties such as porosity and permeability are uniform and isotropic, as are the properties of the reservoir outside the chimney. The initial values of gas pressure and temperature are uniform throughout the chimney and reservoir, and the gas itself is an ideal gas of constant composition. Therefore, a radially symmetric system exists in which the distances, $r$, from the chimney centerline and $z$, from the top of the chimney, are the only spatial coordinates that need be considered.

Now, consider the case in which the chimney permeability is on the order of megadarcys and the reservoir permeability is on the order of millidarcys. The model implicitly assumes the fractured zone with intermediate permeabilities has zero thickness. Then, decrease the pressure at the top center drainage well suddenly by some small amount. The resultant rarefaction wave will be rapidly propagated throughout the chimney, but its velocity beyond the chimney-reservoir interface will be relatively imperceptible. Similarly, the vertical pressure gradient inside the chimney along the chimney-reservoir interface $(\partial p / \partial z)$ will be negligible compared to the horizontal gradient in the reservoir just outside the interface $(\partial p / \partial r)$. This permits the approximation that the perturbed pressure is uniform over the entire interface (if gravity is neglected). Also assume that the pressure at the drainage well remains at a value slightly less than that at the interface. Therefore gas flows from the reservoir into the chimney and up the well at a constant rate. Heat transfer from the porous material in the chimney and reservoir maintains isothermal flow. The gas flow in the chimney is essentially incompressible if the chimney pressure differential is sufficiently small.

All assumptions are compatible with the existence of Darcy flow within the reservoir and chimney. The flow velocity, $v$, at a point along a streamline is therefore given by the relation (again neglecting gravity):

$$
\mathrm{v}=-\frac{\mathrm{K}}{\mu \phi} \frac{\partial \mathrm{p}}{\partial \mathrm{s}}
$$

where $\mathrm{K}$ is the permeability, $\mu$ the viscosity, $\phi$ the porosity and $(\partial \mathrm{p} / \partial \mathrm{s})$ the local pressure gradient along the streamline.

Next, assume that the reservoir pressure is uniform, and that the pressure may be considered uniform over the entire reservoir-chimney interface. Then the pressure distribution in the reservoir outside the chimney is independent of the coordinate, $z$, and is a function of only $\mathbf{r}$ and $t$. Consequently, the uniform properties of the reservoir, and Eq. (1), $v$ is independent of $z$ and is a function of only $r$ and $t$ within the reservoir. Therefore the gas velocity entering the chimney, $v_{i}$, is uniform over the entire 
chimney-reservoir interface. For isothermal, approximately incompressible flow, this means that the flux density entering the chimney is similarly uniform. Therefore the volumetric flow rate into the chimney through an elemental area with height, $\mathrm{dz}$ is:

$$
d q_{i}=(2 \pi R d z) v_{i}
$$

through the interval $\left(0<z_{1}<z_{1}\right)$ is

$$
\mathrm{q}_{\mathrm{i}}=2 \pi R z_{1} \mathrm{v}_{\mathrm{i}}
$$

and into the entire chimney is

$$
Q_{i}=2 \pi R H v_{i}
$$

For steady, incompressible flow, Eq. (4) also gives the solution for the total flow rate out of the chimney. The direct proportional relation between $Q_{i}$ and $H$ might appear to differ from the result for the production rate of partially penetrating wells in uniform reservoirs (which corresponds to the uniform chimney). Beyond the first few feet of sand (below the well bottom) the additional layers of sand give successively decreasing contributions to the production from the well. This effect is associated with the nonuniform flux density at the well inlet (see Ref. 2, p. 269-270 and 273). Furthermore, the solution (Ref. 2, p. 270-271 and Ref. 3) shows a transition from spherical flow (with nonuniform flux distribution) in the vicinity of a "nonpenetrating" well (a chimney) to radial flow (with uniform flux density) near the external boundary (chimney reservoir interface). Since $H$ is generally greater than $R$, the constant pressure interface imposes the uniform radial flow condition relatively close to the well.

If the solution for a short disk is applied to a tall cylinder, the length of the streamlines within the chimney is such that $L(0) \square R, L(H)=R+H$ and $L(z) R+z$. Thus the approximation:

$$
L(z)=R+z
$$

can be made.

Assuming that the transit time for a rarefaction wave to travel throughout the chimney is approximately zero (it is exactly zero for incompressible flow), and that the pressure differential $\Delta \mathrm{p}$ between the chimney drainage well and the chimneyreservoir interface is kept at a constant value, then Eq. (1) may be integrated and 
combined with Eq. (5) to give the following relation for the average velocity $\bar{v}(z)$ along a given streamline that enters the chimney at $\mathrm{z}$ :

$$
\bar{v}(z)=-\frac{K}{\mu \phi}\left[\frac{\int_{0}^{L(z)}(\partial p / \partial s) d s}{L(z)}\right]=-\frac{K}{\mu \phi}\left(\frac{\Delta p}{R+Z}\right) .
$$

It must be noted that this is the spatial average velocity which is not, in general, equal to the usual definition of average velocity: Distance divided by transit time. This assumption is more crude than that implicit in Eq. (5). Nevertheless, in the interest of avoiding complex mathematics like that in Refs. 2 and 3 , the transit time along a given streamline through the chimney can be defined as:

$$
t(z)=L(z) / \bar{v}(z) \text {. }
$$

Then the transit time along the $z=0$ streamline is a unit reference time. It follows that Eqs. (5) through (7) may be combined to give a dimensionless time:

$$
t^{*}(z)=\frac{t(z)}{t(0)}=\left(1+\frac{z}{R}\right)^{2}
$$

At zero time the chimney is filled with radioactive gas and the gas in the reservoir is free of radioactivity. If there is no diffusion or dispersion during the purging process, purging is a simple function of fluid displacement. In general, as radioactive gas is being purged from the chimney, radioactive gas will flow through one portion $A_{r}$ of the drainage well area $A_{0}$ and "clean gas" will flow through the remaining area $A_{C}$ :

$$
A_{r}(t)+A_{c}(t)=A_{0}
$$

Let $\mathrm{z}$, be the coordinate of the streamline that forms the boundary between the purged and unpurged portions of the chimney. Then from Eqs. (8) and (9),

$$
\begin{array}{lll}
\mathrm{z}_{1}=0 & \text { for } & 0 \leq \mathrm{t}^{*} \leq 1, \\
0<\mathrm{z}_{1}<\mathrm{H} & \text { for } & 1<\mathrm{t}^{*}<[1+(\mathrm{H} / \mathrm{R})]^{2},
\end{array}
$$

and

$$
z_{1}=H \quad \text { for } \quad t^{*}=[1+(H / R)]^{2} \text {. }
$$

If $A_{c} / A_{0}$ is assumed equal to $z_{1} / H$, the relation used by Higgins and Rodean to

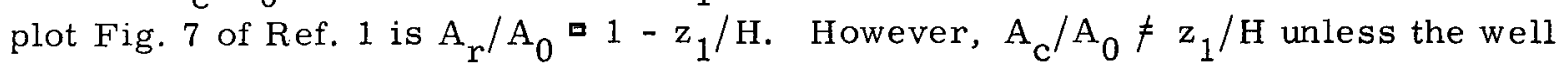
flux distribution is uniform (which it is not as noted above).

A different approach that recognizes nonuniform flux distribution at the drainage well utilizes Eq. (6). The average of $\bar{v}(z)$ for all the streamlines becomes: 


$$
\overline{\bar{v}}(\mathrm{H})=\frac{1}{\mathrm{H}} \int_{0}^{\mathrm{H}} \overline{\mathrm{v}}(\mathrm{z}) \mathrm{dz}=-\frac{\mathrm{K} \Delta \mathrm{p}}{\mu \phi \mathrm{H}} \ln \left(\frac{\mathrm{R}+\mathrm{H}}{\mathrm{R}}\right) .
$$

Similarly, the average of $\bar{v}(z)$ for the unpurged portion of the chimney is:

$$
\overline{\bar{v}}\left(z_{1}\right)=\frac{1}{H-z_{1}} \int_{z_{1}}^{H} \bar{v}(z) d z=-\frac{K \Delta p}{\mu \phi\left(H-z_{1}\right)} \ln \left(\frac{R+H}{R+z_{1}}\right) .
$$

Assuming that $\overline{\bar{v}}(\mathrm{H})$ and $\overline{\bar{v}}\left(z_{1}\right)$ are directly proportional by the same factor $\alpha$ to the average velocities through $A_{0}$ and $A_{r}$, respectively, the steady incompressible flow ratio are:

$$
\begin{aligned}
& Q_{i}=\alpha A_{0} \overline{\bar{v}}(H) \\
& Q_{i}-q_{1}=\alpha A_{r} \overline{\bar{v}}\left(z_{1}\right) .
\end{aligned}
$$

Then Eqs. (3), (4) and (11) through (14) may be combined to give:

$$
\frac{A_{r}}{A_{0}}=\frac{\ln \left(\frac{R+H}{R+z_{1}}\right)}{\ln \left(\frac{R+H}{R}\right)}
$$

If the concentration of radioactivity in the gas flowing through $\mathrm{A}_{\mathrm{r}}$ is defined as unity, then the mean concentration over the total well area $A_{0}$ is, from Eq. (15),

$$
C\left(z_{1}\right)=\frac{A_{r}}{A_{0}}=\frac{\ln \left(\frac{R+H}{R+z_{1}}\right)}{\ln \left(\frac{R+H}{R}\right)} .
$$

This gives $C\left(z_{1}\right)=1$ when $z_{1}=0$ and $C\left(z_{1}\right)=0$ when $z_{1}=H$. Now, from Eqs. (10a) through $(10 \mathrm{c})$ and $(16)$, if the concentration of radioactivity in the gas leaving the chimney is expressed as a function of time,

$$
\begin{array}{lll}
C\left(t^{*}\right)=1 & \text { for } & 0 \leq t^{*} \leq 1 \\
C\left(t^{*}\right)=\frac{\ln \left(\frac{R+H}{R \sqrt{t^{*}}}\right)}{\ln \left(\frac{R+H}{R}\right)} & \text { for } & 1 \leq t^{*} \leq\left(1+\frac{H}{R}\right)^{2} .
\end{array}
$$

Then from Eqs. (8), (17a) and (17b), the average radioactive concentration during the entire purging process can be found:

$\bar{C}=\left(\frac{R}{R+H}\right)^{2} \int_{0}^{t^{*}=\left(1+\frac{H}{R}\right)^{2}} C\left(t^{*}\right) d t^{*}=\left(\frac{R}{R+H}\right)^{2}\left[1+\int_{t^{*}=1}^{t^{*}=\left(1+\frac{H}{R}\right)^{2}} \frac{\ln \left(\frac{R+H}{R \sqrt{t^{* k}}}\right) d t^{*}}{\ln \left(\frac{R+H}{R}\right)}\right]$ 
To make the integration easier, introduce the variable,

$$
\mathrm{s}=(\mathrm{R}+\mathrm{H}) / \mathrm{R} \sqrt{\mathrm{t}^{*}}
$$

and substitute it into Eq. (18) to give,

$$
\bar{C}=\left(\frac{R}{R+H}\right)^{2}-\frac{2}{\ln \left(\frac{R+H}{R}\right)} \int_{s=1+\frac{H}{R}}^{s=1} \frac{\ln s d s}{s^{3}} .
$$

After performing the integration, ${ }^{4}$ the solution is:

$$
\bar{C}=\frac{1-\left(\frac{R}{R+H}\right)^{2}}{2 \ln \left(\frac{R+H}{R}\right)} .
$$

Initially, the concentration within the chimney was unity. Therefore, the number of chimney volumes of gas expended in purging is:

$$
\mathrm{N}=1 / \overline{\mathrm{C}} \text {. }
$$

Four numerical examples for $H / R$ values of $2,4,5$, and 10 , which should cover the range of interest for most nuclear chimneys, are given in Tables I'and II, and are shown graphically in Fig. 1. Other examples for $H / R$ values of $2.5,2.875,3.8$, and

Table I. Numerical computations for Eq. (17b):

\begin{tabular}{rcccc}
\hline \multicolumn{5}{c}{$\ln \left(\frac{\mathrm{R}+\mathrm{H}}{\mathrm{R} \sqrt{\mathrm{t}^{*}}}\right)$} \\
$\left.\mathrm{C}\left(\mathrm{t}^{* *}\right)=\frac{\mathrm{R}+\mathrm{H}}{\mathrm{R}}\right)$ & & \\
\hline $\mathrm{t}^{*}$ & $\mathrm{H} / \mathrm{R}=2$ & $\mathrm{H} / \mathrm{R}=4$ & $\mathrm{H} / \mathrm{R}=5$ & $\mathrm{H} / \mathrm{R}=10$ \\
1 & 1.000 & 1.000 & 1.000 & 1.000 \\
4 & 0.369 & 0.569 & 0.615 & 0.710 \\
9 & 0.000 & 0.317 & 0.387 & 0.542 \\
16 & - & - & 0.102 & 0.422 \\
25 & - & - & 0.000 & 0.328 \\
36 & - & - & - & 0.252 \\
49 & - & - & - & 0.188 \\
64 & - & - & - & 0.133 \\
81 & - & - & - & 0.084 \\
100 & - & - & - & 0.040 \\
121 & - & & & 0.000 \\
\hline
\end{tabular}


Table II. Numerical computations for Eqs. (21) and (22):

\begin{tabular}{ccc}
\multicolumn{4}{c}{$\overline{\mathrm{C}}=\frac{1-\left(\frac{\mathrm{R}}{\mathrm{R}+\mathrm{H}}\right)^{2}}{2 \ln \left(\frac{\mathrm{R}+\mathrm{H}}{\mathrm{R}}\right)}$ and $\mathrm{N}=1 / \overline{\mathrm{C}}$} \\
\hline $\mathrm{H} / \mathrm{R}$ & $\overline{\mathrm{C}}$ & $\mathrm{N}$ \\
0.2 & 0.404 & 2.48 \\
0.4 & 2.98 & 3.36 \\
0.5 & 0.271 & 3.69 \\
10 & 0.207 & 4.83 \\
\hline
\end{tabular}

5.0, which correspond to various test assemblies, are plotted in Fig. 2 and Figs. 5 through 14 for comparison with both the uniform mixing model (described below) and the various test data.

The classic uniform mixing model is described by the equation:

$$
C_{t}=\exp -\left(V_{t} / V_{0}\right)
$$
where $C_{t}$ is the concentration at any time, $t, V_{t}$ the total production up to time, $t, V_{0}$ the chimney volume, and with an initial concentration set at unity. The decrease in concentration as a function of chimney volume produced is shown in Figs. $2 \mathrm{a}$ and $2 \mathrm{~b}$. Compared with concentrations deduced from the displacement model (e.g., Eq. 17b). The uniform mixing concentrations are independent of chimney shape.

These two models are compared qualitatively in Figs. $3 a, b$, and c. Initially, both are the same as shown in Fig. 3a, however, as production proceeds, gas from the nearer chimney walls sweeps all contaminated gas out in front of it, successively purging deeper and deeper into the chimney. However, if mixing is rapid all of the gas is contaminated equally at any given time, but the concentration decreases exponentially.

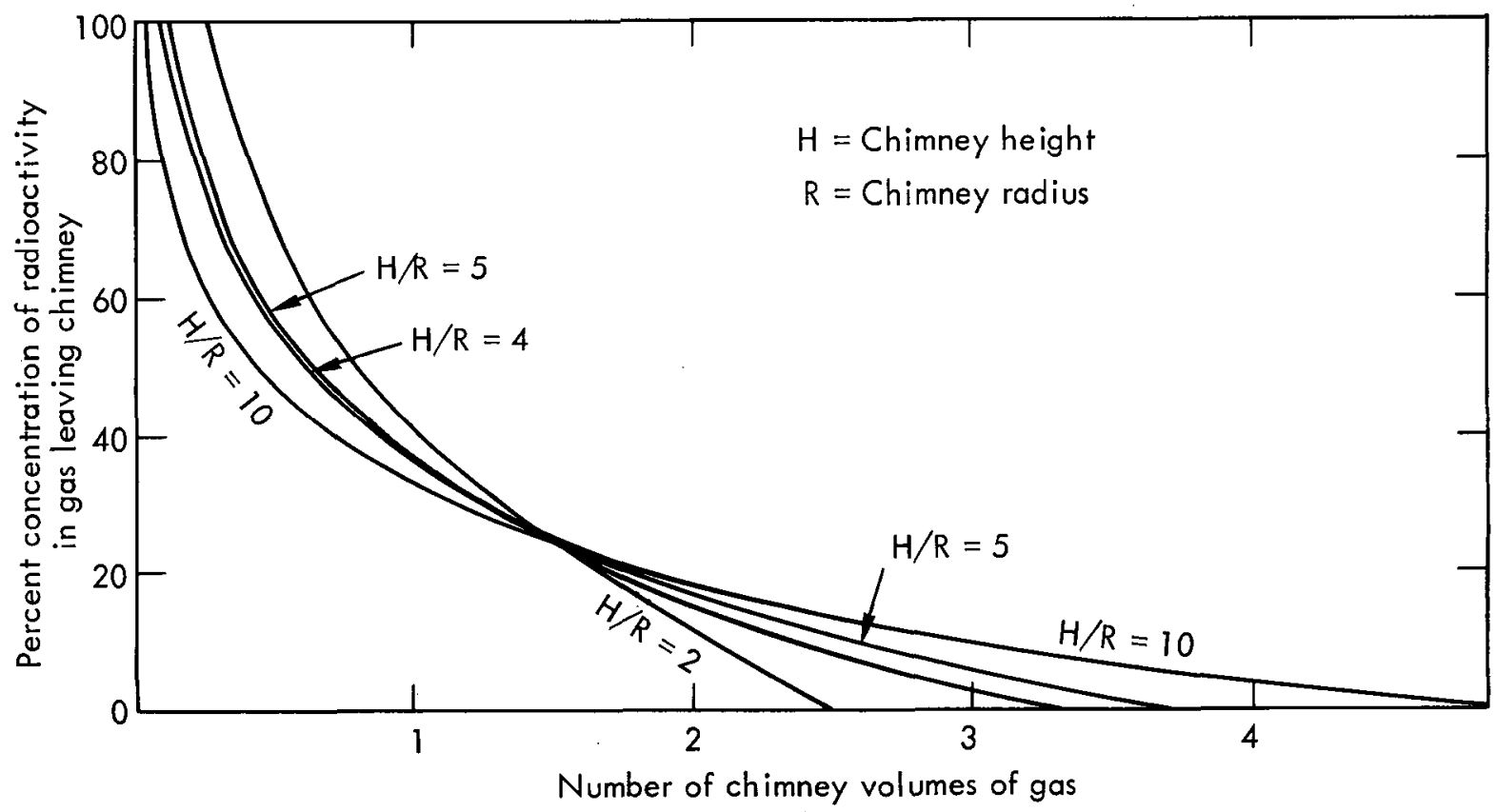

Fig. 1. Estimated radioactivity concentration (initial value $=100$ percent) during well production. 


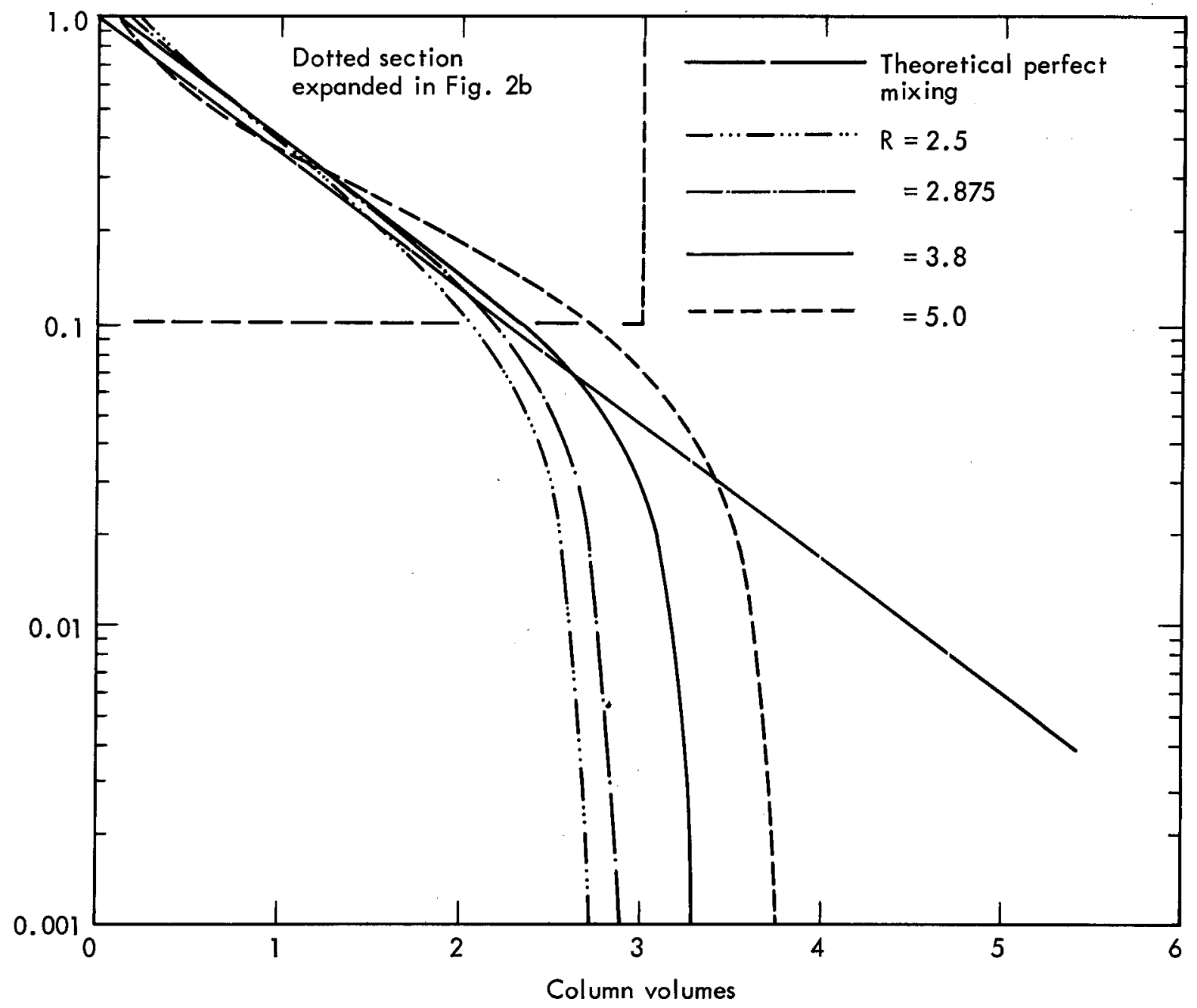

Fig. 2a. Comparison of theoretical values of different R's to perfect mixing.

In the above, the time unit $t^{*}$ has been related to the time required for transit through the chimney along the $z=0$ streamline. The time required for removal of one chimney volume of gas has not been related except in an indirect manner through $\overline{\mathrm{C}}$ and the $\mathrm{N}$ that is obtained by the integration of $\mathrm{C}\left(\mathrm{t}^{*}\right)$ with respect to $\mathrm{t}^{*}$ between the limits of $t^{*}(0)$ and $t^{*}(H)$, the period of purging. Now $t^{*}(H), \bar{C}$ and $N$ per Eqs. (8), (21) and (22) are functions of $R$ and $H$. If all parameters are held constant except $H$, it follows that the time for purging is proportional to $\mathrm{H}$ and $\mathrm{N}$ :

$$
\mathrm{t}^{*}(\mathrm{H})=\beta \mathrm{HN}
$$

where $\beta$ is a constant of proportionality. Then from Eq. (24), for chimneys a and b,

$$
\frac{\mathrm{t}^{*}\left(\mathrm{H}_{\mathrm{a}}\right)}{\mathrm{t}^{* *}\left(\mathrm{H}_{\mathrm{b}}\right)}=\frac{\mathrm{H}_{\mathrm{a}} \mathrm{N}_{\mathrm{a}}}{\mathrm{H}_{\mathrm{b}} \mathrm{N}_{\mathrm{b}}} .
$$

Then if $\mathrm{t}^{*}(\mathrm{H}), \mathrm{H}$ and $\mathrm{N}$ are known for one case, Eq. (25) can be used as well as Eq. (8) to find $t^{*}(H)$ for another. This is demonstrated in Table III with $H=5 R$ as the reference case. 


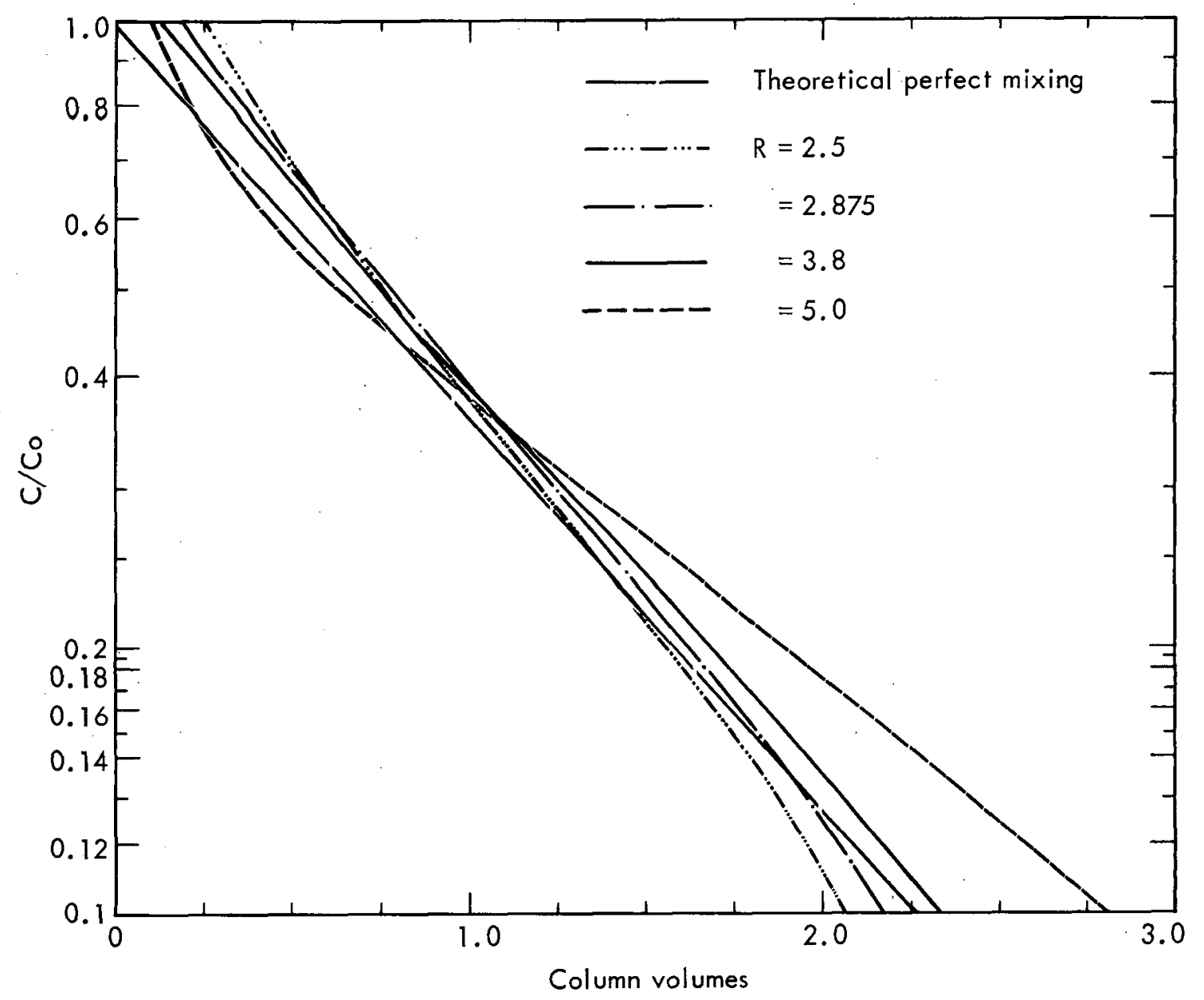

Fig. 2b. Expanded insert from Fig. 2a.

Table III. Comparison of Eqs. (8) and (25) for time of purging.

\begin{tabular}{lccc} 
& $\mathrm{H} / \mathrm{R}=2$ & $\mathrm{H} / \mathrm{R}=5$ & $\mathrm{H} / \mathrm{R}$ × 10 \\
$\mathrm{t}^{*}(\mathrm{H})$ per Eq. (8) & 9 & 36 & 121 \\
$\mathrm{t}(\mathrm{H})$ per Eq. (25) & 11.4 & 36 & 94.2 \\
Eq. (25) error & $+26.7 \%$ & $0 \%$ & $-22.2 \%$ \\
\hline
\end{tabular}

Therefore, the mathematical model does not scale from one chimney to another without some error, but this is not surprising in view of the many approximations. The chimneys with smallest $H / R$ should be most nearly approximated by this treatment.

In an attempt to model the purging of radioactivity from a nuclear chimney, a series of tests were performed and are compared with the theoretical models. 


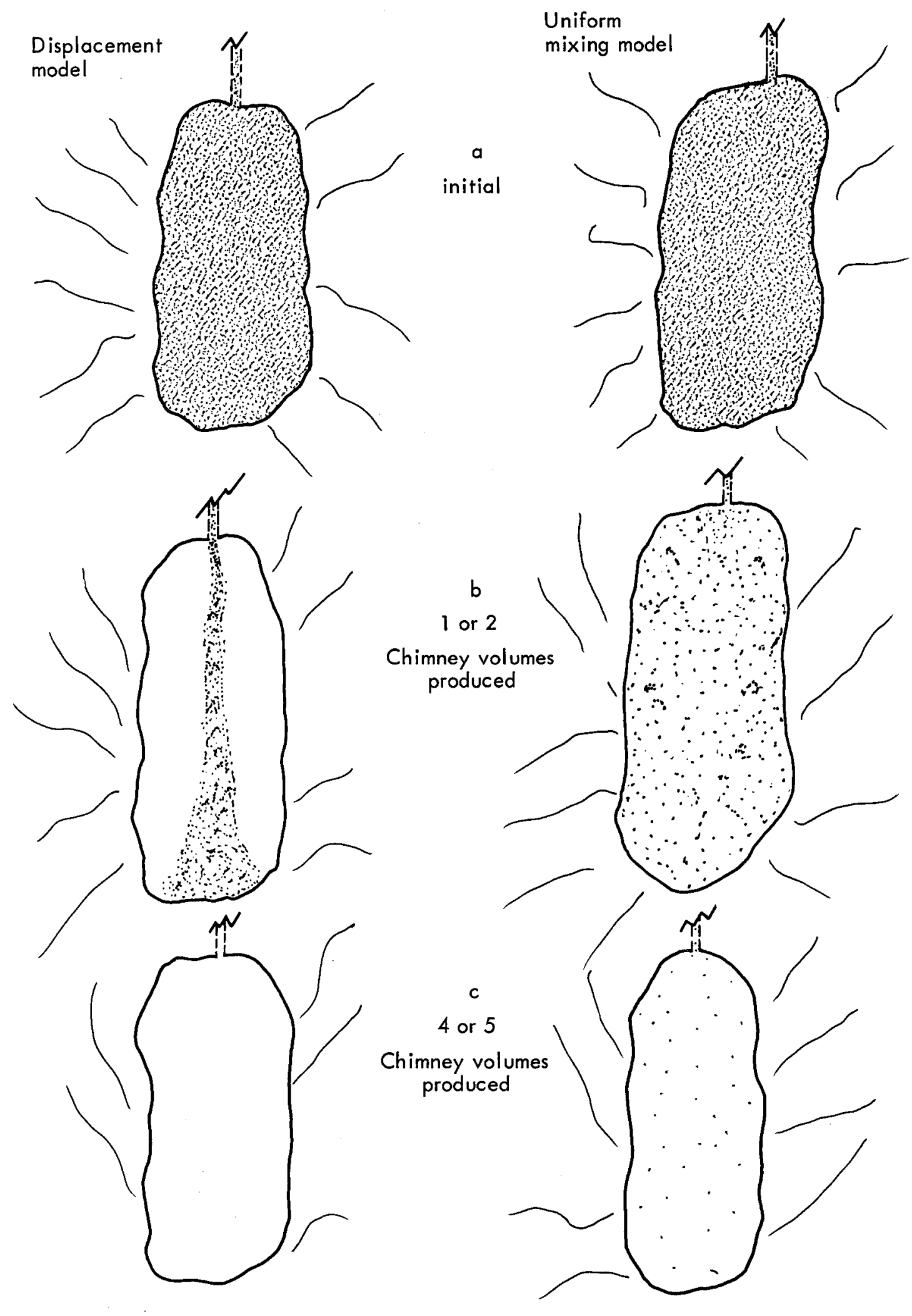

Fig. 3a, 3b, and 3c. Comparison of both models is shown above. 


\section{Description}

The apparatus used to test the models is shown in Figs. 4 and 5. It consists of a set of concentric cylinders set in a glass cylindrical-walled bowl. The innermost, which has a drain-line beneath, represents the chimney and production well. For some test runs this inner cylinder was filled with glass beads; for other test runs the beads were removed to permit mechanical stirring of the solutions. The inner cylinder is separated from the next sand-filled region by a stainless steel screen and, during setup, by a lucite barrier tube. The sand-filled region representing the gas reservoir is separated from the outer container wall by a perforated lucite cylinder so there is a manifold for uniform flow surrounding the low permeability sand-filled region.

The height and diameters of the innermost cylinder and sand were different in the runs to simulate various $h$ to $r$ ratios of nuclear chimneys.

Water was introduced into the outermost region flooding the annulus and low permeability sand to a level just below the top of the sand. Dilute sulphuric acid was introduced in the center cylinder to the same level. The central cylinder drain-line representing the production well led through a flow-control valve and recording $\mathrm{pH}$ meter. The dilute acid represented the contaminated gas and the water in the sand represented the uncontaminated gas.

\section{Procedure}

Prior to the start of each flow test, the outer lucite manifold and the thin-walled cylinder were placed in the bowl. Beads were added in the small center cylinder, and sand in the space between it and the outer lucite cylinder. Water and acid were then added.

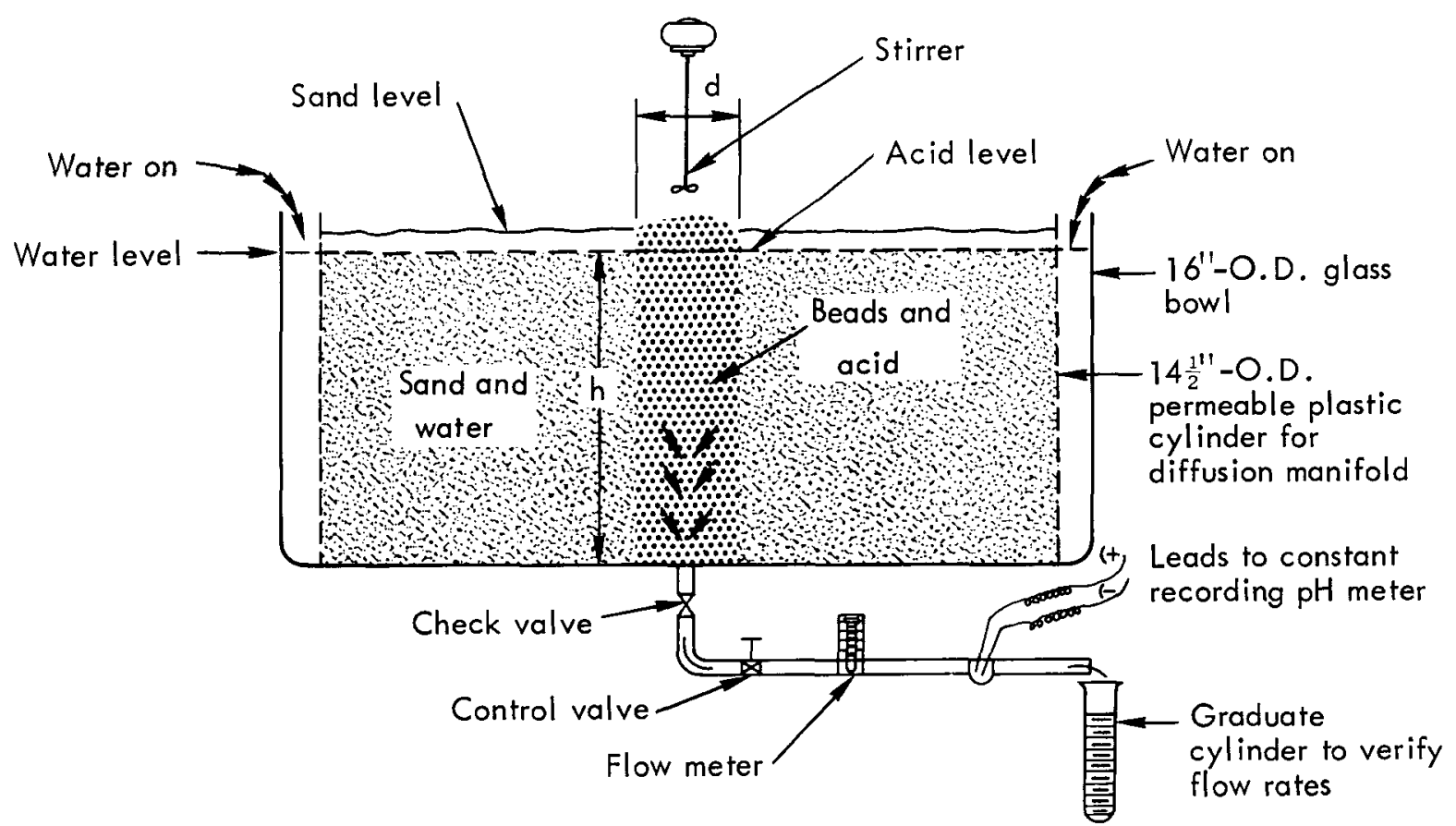

Fig. 4. Cross-section of the apparatus used in testing the models. 

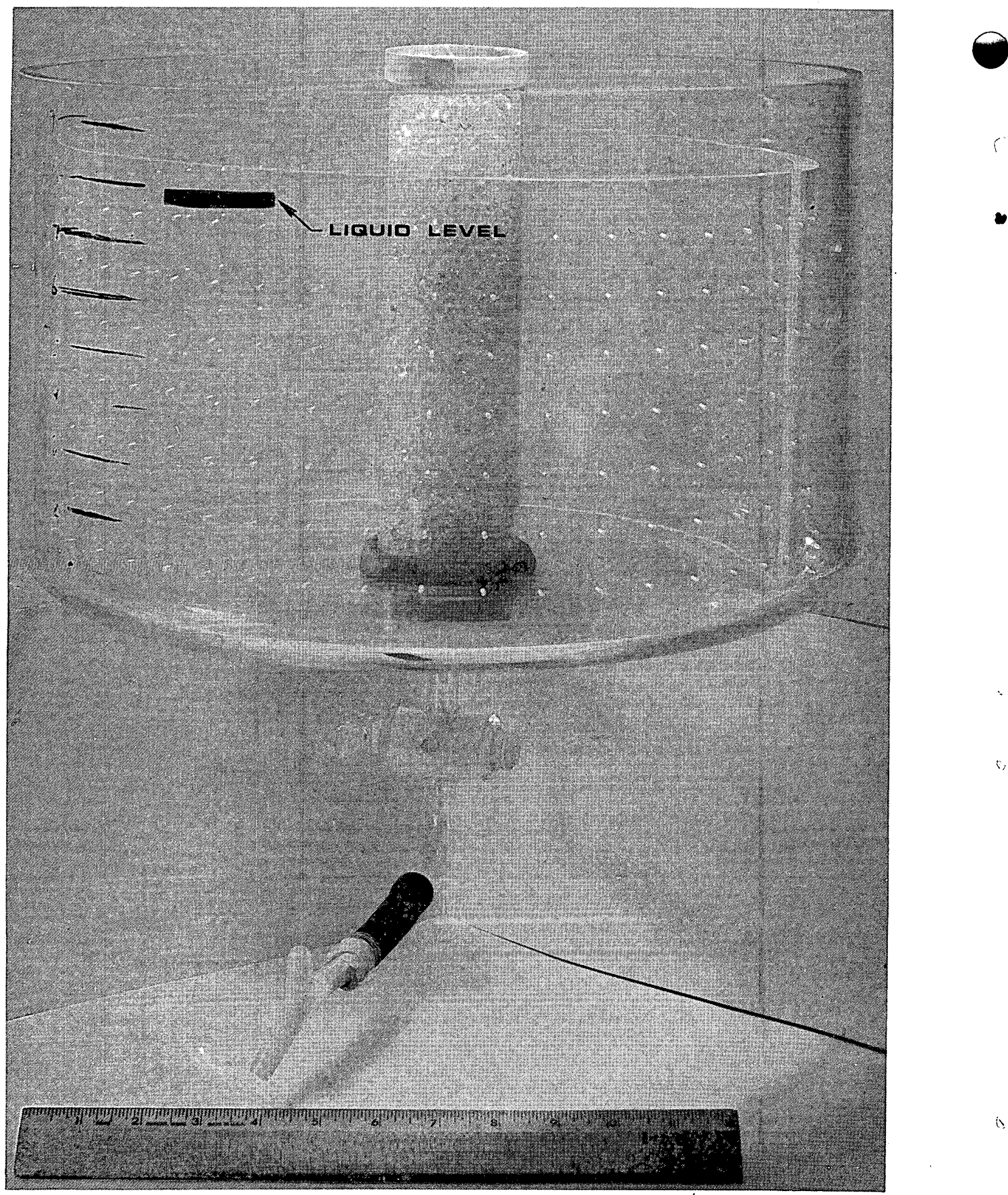


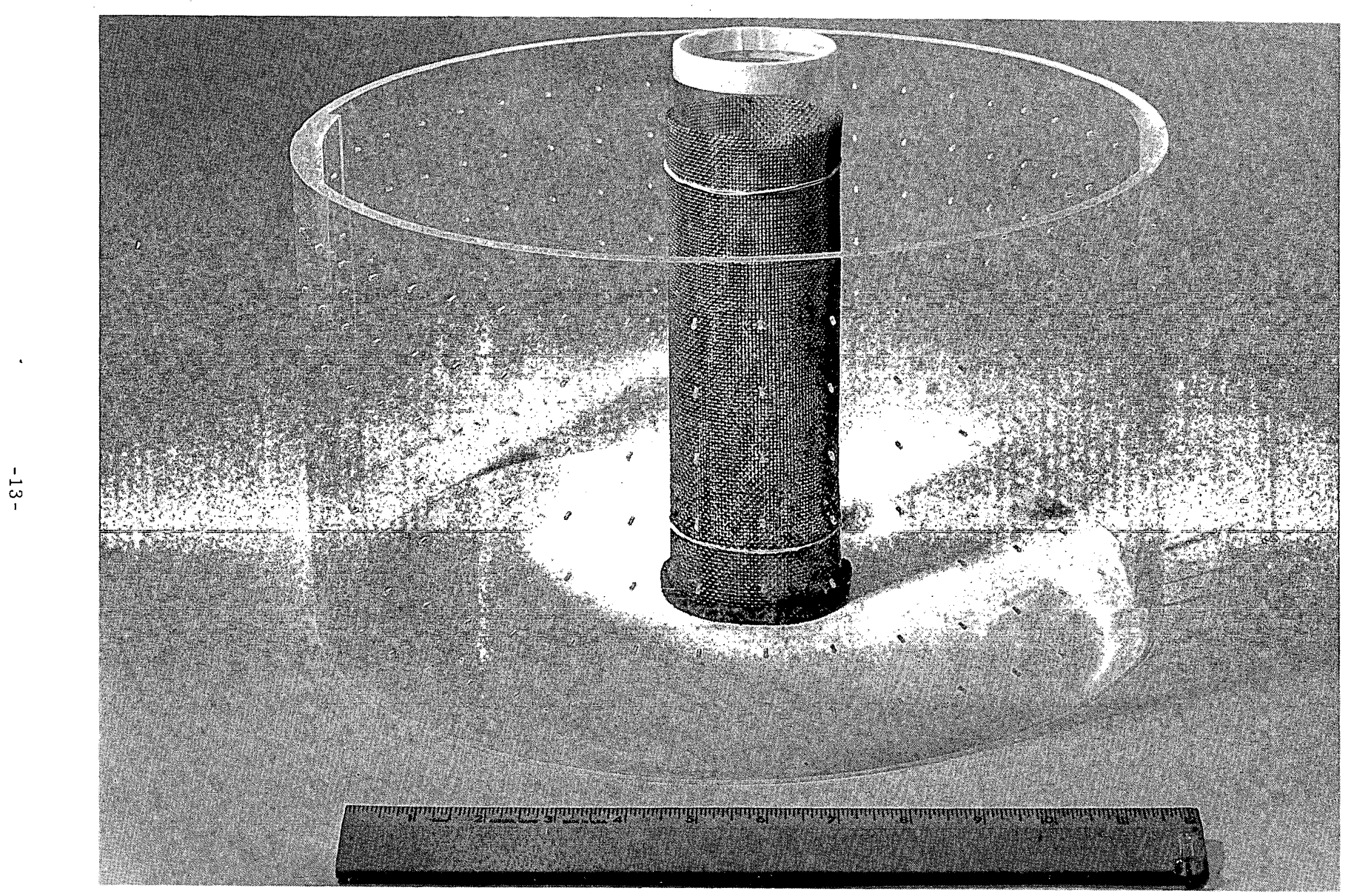

Fig. 5b. The lucite diaphragm and center cylinder with the stainless steel screen holds the sand in place after the cylinder was removed at the start of the run. 


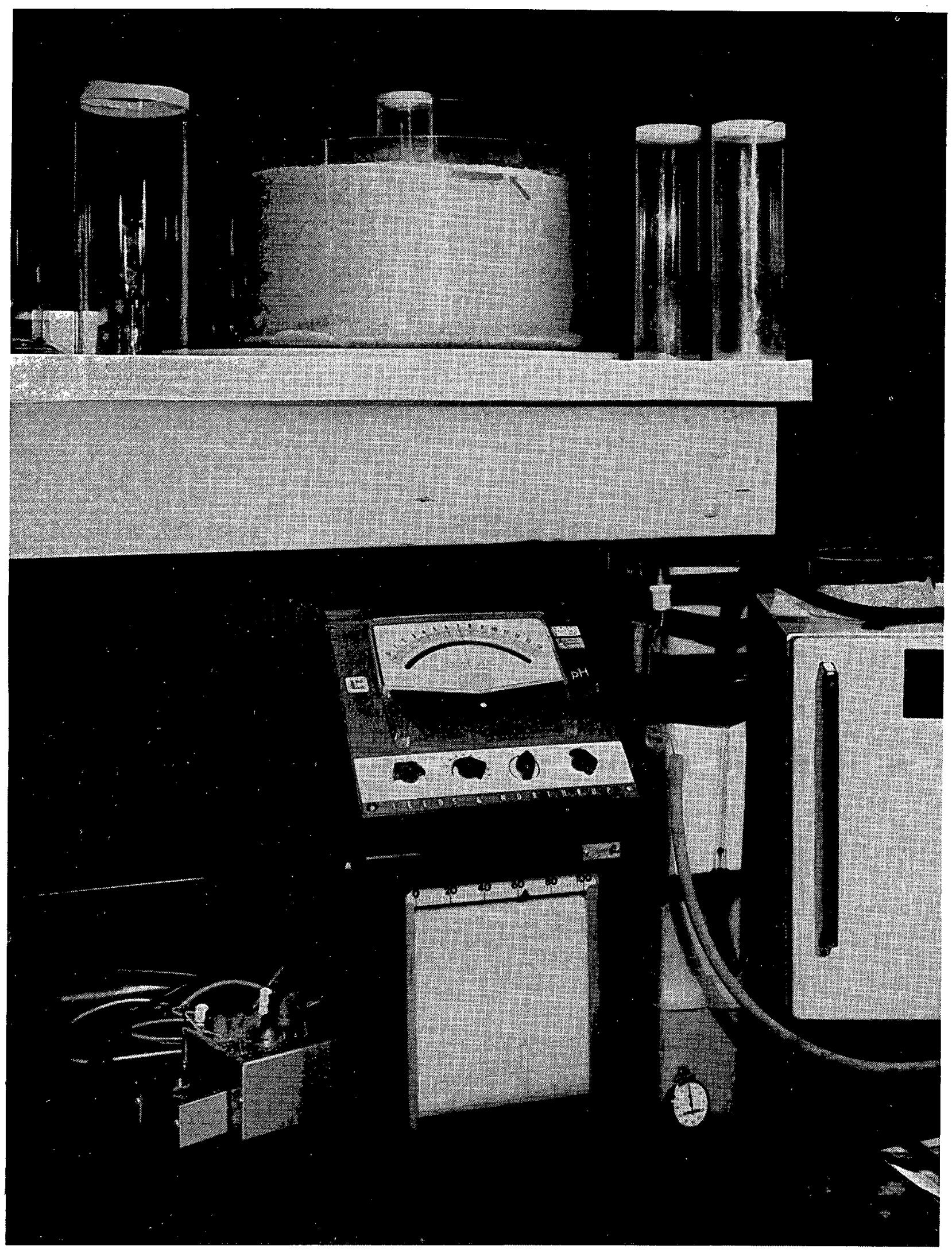

Fig. 5c. The experimental set-up, showing the sand-filled bowl at top with the pH meter and recorder, and the flowmeter and timer at the bottom. 
The flow rate through the micro-valve was adjusted and set, the $\mathrm{pH}$ meter was calibrated, and the water and acid levels were adjusted at about $10 \mathrm{~mm}$ below the sand-bead level, to help prevent "short circuits" across the top of the sand. A timer was started, the ON-OFF valve opened, and the thin-walled barrier cylinder between the "chimney" and production sand gently removed.

The gradual change in $\mathrm{pH}$, from the initial $\mathrm{pH}$ of the starting acid used in the center cylinder to the $\mathrm{pH}$ of the water in the outer area, was recorded on a timed chart. A total of 14 tests were run and the data presented in Table IV and Figs. 6 through 14.

Table IV. Summary of flow test data.

\begin{tabular}{|c|c|c|c|c|c|c|c|c|c|}
\hline $\begin{array}{l}\text { Run } \\
\text { No. }\end{array}$ & $\begin{array}{l}\text { Liquid } \\
\text { height } \\
\text { h } \\
(\mathrm{mm})\end{array}$ & $\begin{array}{l}\text { Cylinder } \\
\text { radius } \\
r \\
(\mathrm{~mm})\end{array}$ & $\underset{(h / r)}{R}$ & $\begin{array}{l}\text { Average } \\
\text { flow } \\
\text { rate } \\
\mathrm{cc} / \mathrm{min}\end{array}$ & $\frac{\mathrm{Vol}}{\mathrm{Acid}}$ & $\frac{\text { ume }}{\substack{\text { Water } \\
\text { cc }}}$ & $\frac{\mathrm{F}}{\text { Acid }}$ & $\frac{\mathrm{pH}}{\text { Water }}$ & $\mathrm{t}^{\mathrm{O}}\left(\right.$ water-acid) $22^{\circ} \mathrm{C}$ \\
\hline 1 & 100 & 40 & 2.5 & $>600.0$ & $150^{a}$ & NA & 0.2 & NA & \multirow{4}{*}{$\begin{array}{l}\text { Coarse sand, } \\
20 \text { mesh, no mani- } \\
\text { fold, fast flow } \\
\text { rates. }\end{array}$} \\
\hline 2 & 100 & 40 & 2.5 & $\sim 100.0$ & 150 & 1100 & 0.2 & 8.7 & \\
\hline 3 & 100 & 40 & 2.5 & $\sim 100.0$ & 160 & 1200 & 2.0 & $6.5^{\mathrm{b}}$ & \\
\hline 4 & 115 & 40 & 2.875 & 170.0 & 180 & 1775 & 1.7 & 8.4 & \\
\hline 5 & 115 & 40 & 2.875 & 92.0 & $180^{\circ}$ & 1770 & 1.7 & 8.4 & \multirow[t]{3}{*}{$\begin{array}{l}\text { Fine sand, } \sim 100 \\
\text { mesh, with lucite } \\
\text { manifold. }\end{array}$} \\
\hline 6 & 100 & 40 & 2.5 & 42.0 & 170 & 1550 & 1.7 & 8.4 & \\
\hline 7 & 152 & 40 & 3.8 & 21.5 & 195 & 2500 & 1.7 & 8.4 & \\
\hline 8 & 152 & 40 & 3.8 & 17.0 & 195 & 2500 & 1.66 & 7.95 & $\left\{\begin{array}{l}\text { Start-up trouble } \\
\text { (seal) }\end{array}\right.$ \\
\hline 9 & 192 & 40 & 4.8 & 20.0 & 270 & 3000 & 1.82 & 8.9 & \multirow[t]{4}{*}{$\begin{array}{l}\text { Aborted, due to } \\
\text { leak. }\end{array}$} \\
\hline 10 & 175 & 35 & 5.0 & 24.0 & 260 & 3700 & 2.25 & 8.9 & \\
\hline 11 & 175 & 35 & 5.0 & 16.0 & 260 & 3750 & 2.00 & 8.9 & \\
\hline 12 & 175 & 35 & 5.0 & 17.0 & 265 & 3750 & 1.42 & 8.9 & \\
\hline 13 & $160^{\mathrm{C}}$ & 32 & 5.0 & 26.0 & 470 & 2780 & 1.58 & $6.2^{\mathrm{d}}$ & $\begin{array}{l}\text { No beads in center } \\
\text { column } \therefore \text { larger } \\
\text { column vol. }\end{array}$ \\
\hline 14 & 160 & 32 & 5.0 & 26.0 & 450 & $2750^{\mathrm{e}}$ & 1.55 & 6.5 & $\begin{array}{l}\text { Run } 14 \text { with stirrer } \\
\text { in center column. } \\
\text { Constant mixing. }\end{array}$ \\
\hline
\end{tabular}

Plotted: $4,5,8,12,13,14$ and theoretical

${ }^{\text {a }}$ Drainage vol. Total acid on to dry beads 175 .

${ }^{b}$ After sitting 12 min. Sand needed more washing. Later runs showed little $\mathrm{pH}$ change, even after the system sat for hours.

${ }^{\mathrm{c}}$ Well below sand level of $190 \mathrm{~mm}$.

$\mathrm{d}_{\text {De-ionized water. }}$

${ }^{\mathrm{e}}$ Of the $4550 \mathrm{cc}$ originally added to dry sand, $1800 \mathrm{cc}$ was held up in the wet sand after draining and standing for $10 \mathrm{~min}$. 


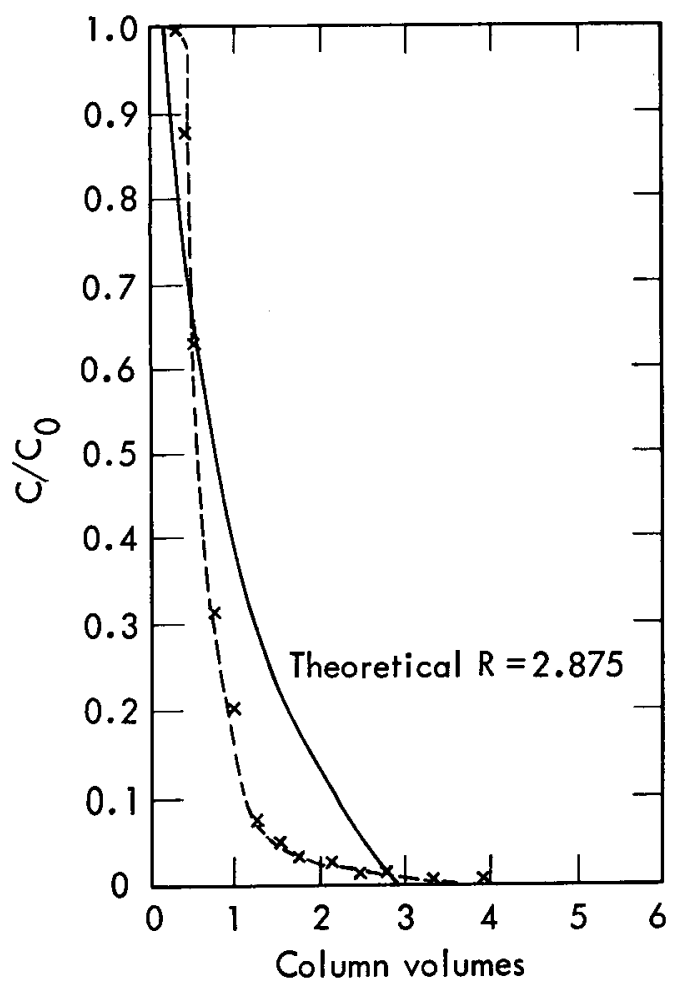

Fig. 6. Results of the $R=2.875$ flow test.

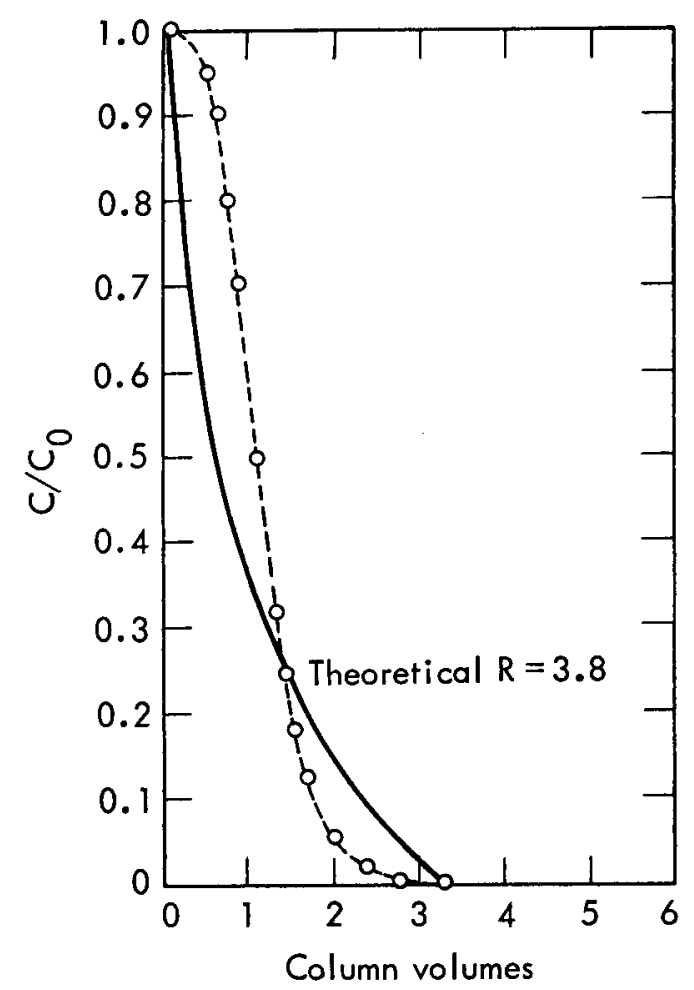

Fig. 8. Results of the $\mathrm{R}=3.8$ flow test.

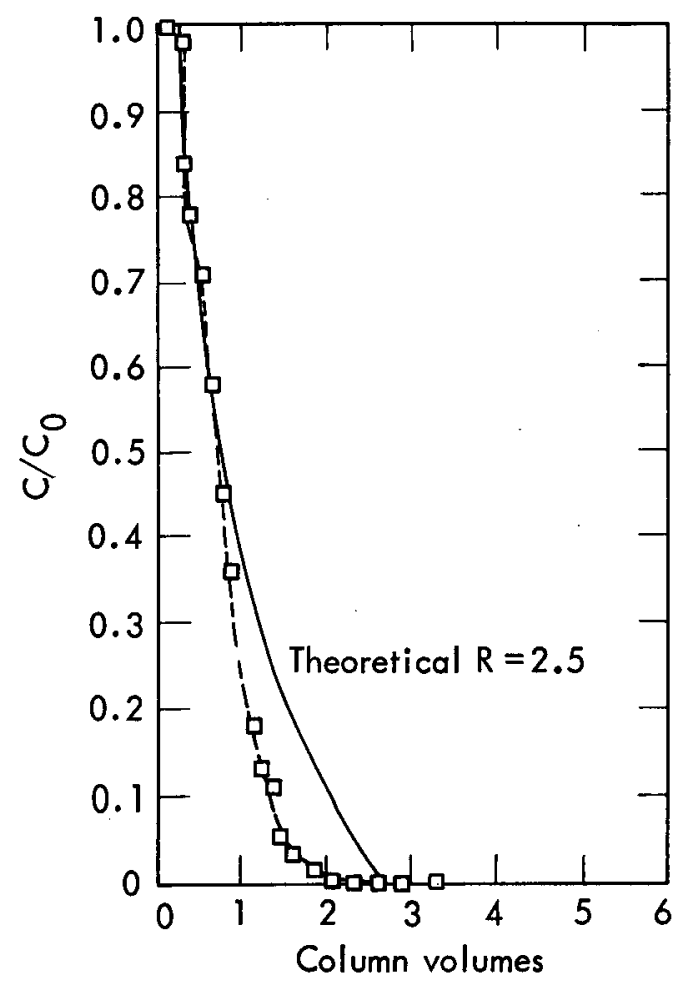

Fig. 7. Results of the $R=2.5$ flow test.

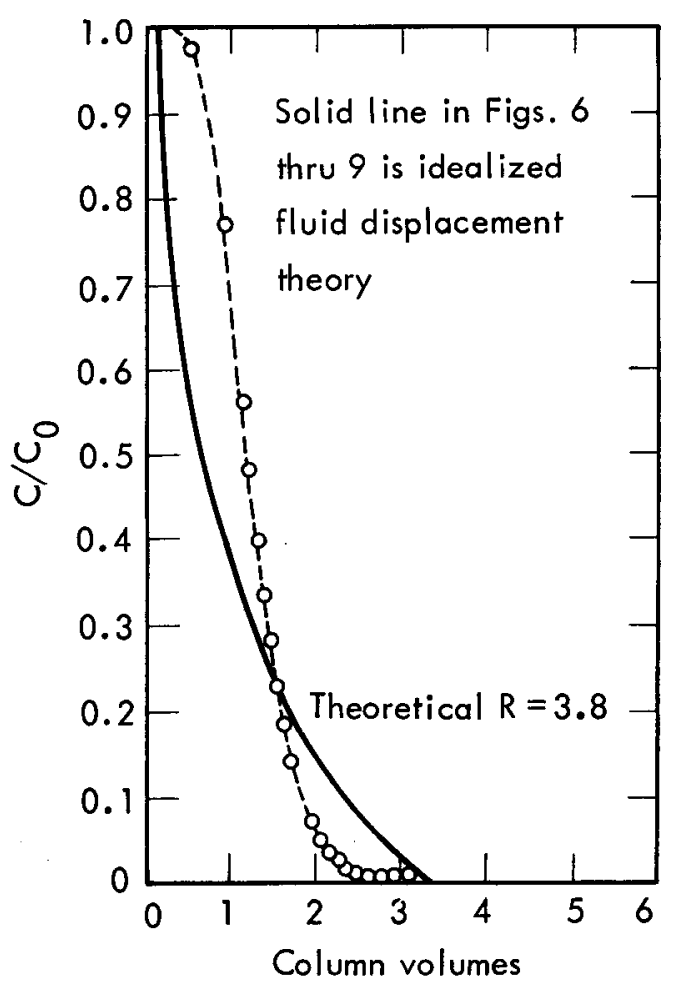

Fig. 9. Results of the $R=3.8$ flow test (slow rate) based on the Higgins Rodean fluid-displacement theory. 


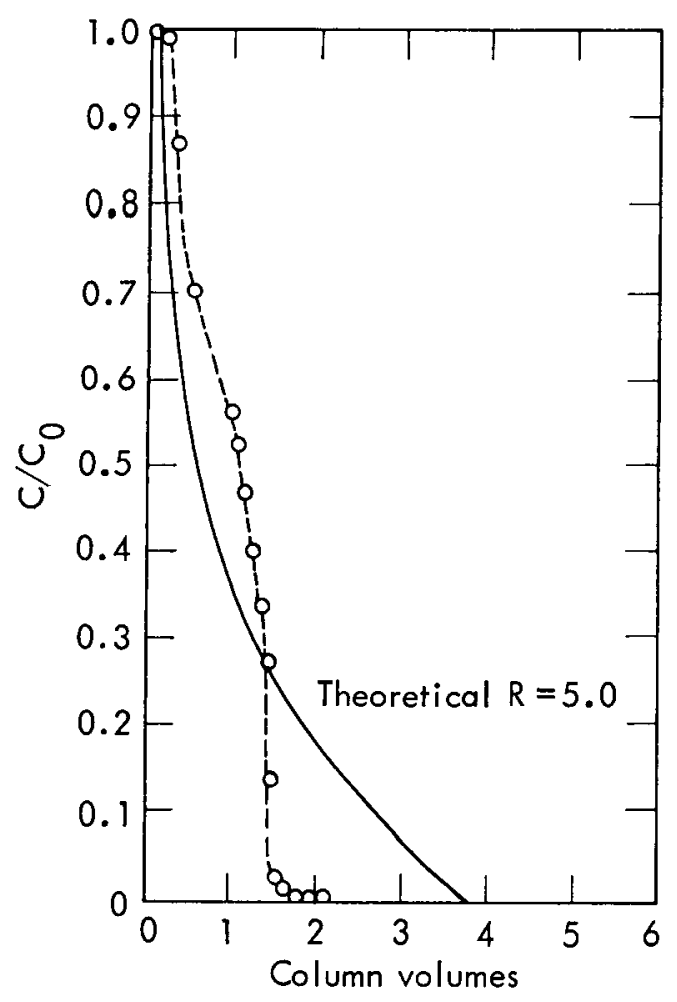

Fig. 10. Results of the $R=5.0$ medium fast-flow test.

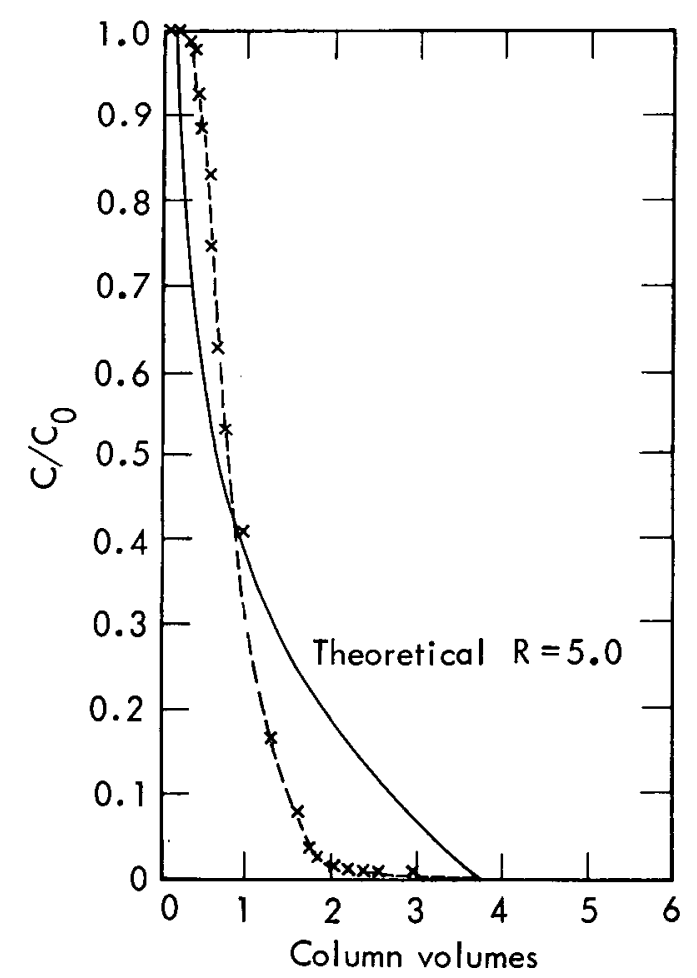

Fig. 12. Results of the $R=5.0$ very slow flow test with high-acid.

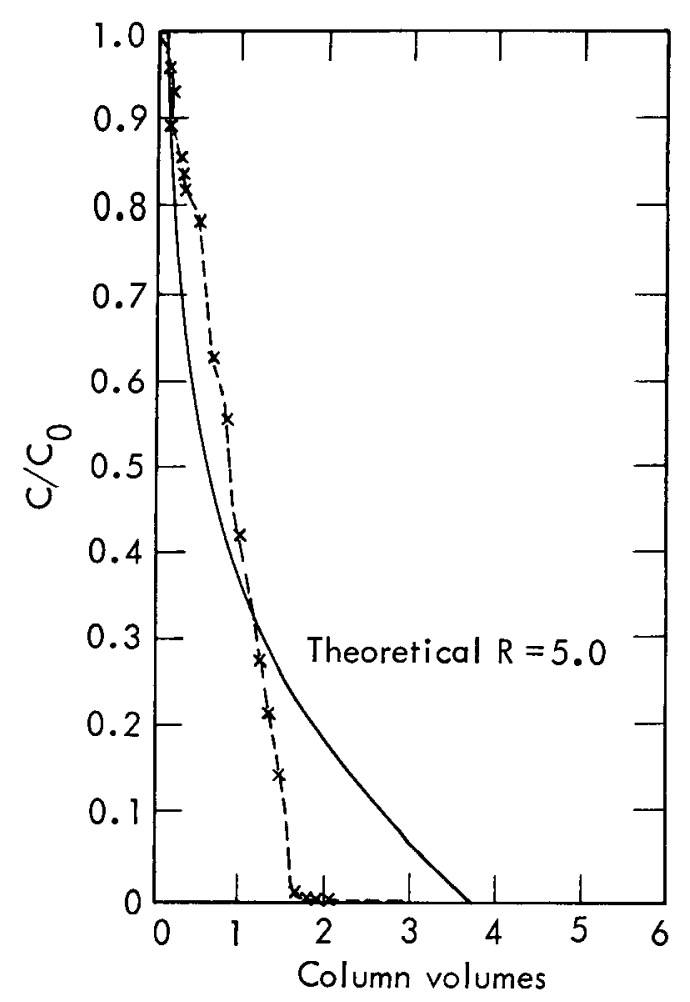

Fig. 11. Results of the $R=5.0$ slow - flow low-acid flow test.

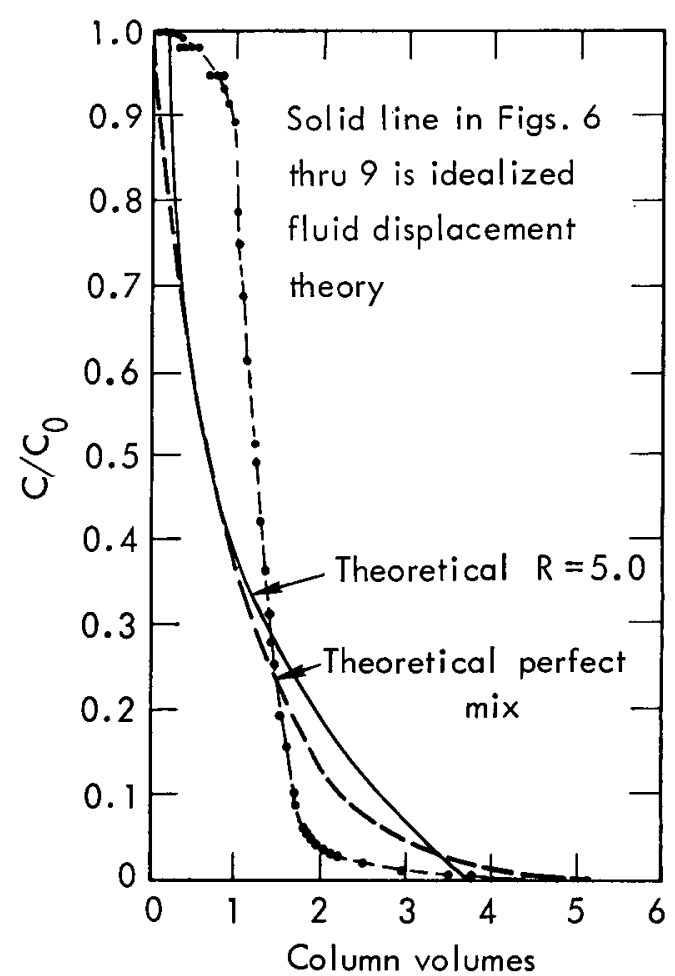

Fig. 13. Results of the $R=5.0$ very slow flow test. (No beads, larger chimney volume, purer water, and high acid.) 


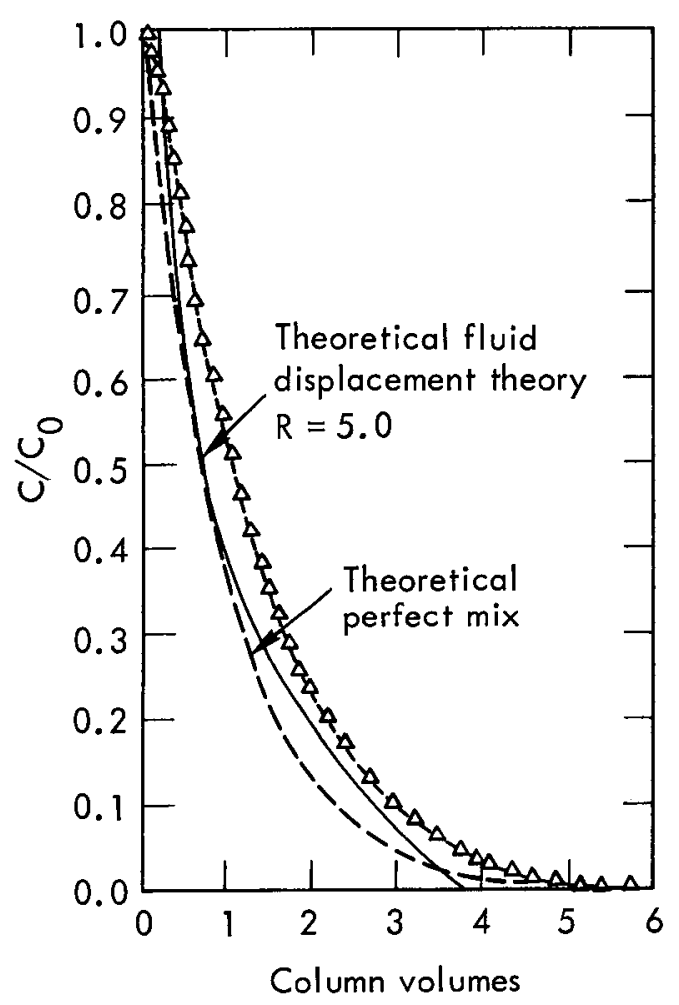

Fig. 14. Results of the $R=5.0$ very slow flow test "perfect mix." (No beads, larger chimney volume, and constant stirring.)
The acid concentration determined from $\mathrm{pH}$ readings represents the radioactivity concentration and its decrease simulates the decrease in radioactivity during gas production.

\section{Discussion}

The first model tested in runs 1 through 12 is "simple fluid-displacement" without diffusion or dispersion. With this model there is no perceptible change in the concentration in fluid first leaving the chimney. Then, as the flow continues, the concentration decreases fairly rapidly, as indicated in Figs. 6 through 12, which depict the theoretical model for displacement and relate $\mathrm{C} / \mathrm{C}_{0}$ to column volume. In a finite time, zero concentration is reached and the chimney is completely purged. In the simplified theory, it is assumed that there is a piston-like displacement with no dispersion or diffusion along each infinitesimal line. However, in

view of the complex geometry followed by the stream lines from the walls of the cylinder to a point in one end of the cylinder, the concentration varies with time in a complex way. [See Eqs. (17a) and (17b).]

These experiments show that the concentration in the discharge remains relatively high at first, and then begins to drop fairly rapidly. This is qualitative, if not quantitative agreement with the simple fluid-displacement model theory. However, the concentration is significantly above zero at late times. The chimney has not been completely purged and the model tends to resemble the perfect mix situation, in place of the simple fluid-displacement model. Mixing becomes evident in the later stages because of the dispersion and diffusion that has occurred and because the theory is only approximate.

In Figs. 6 through 14, the change in acid concentration versus the cumulative flow measured in chimney (inner cylinder) volumes for each of the test runs and is to be compared with the solid lines from the calculations best fitting and test situation. The dashed lines in Figs. 13 and 14 are for perfect mixing in the chimney.

Run 4 was an anomaly, because the integral under the curve was much greater than one (one full chimney volume, over $\mathrm{C} / \mathrm{C}_{0}$ range). (Evidently, an error in $\mathrm{pH}$ meter calibration occurred during this run.) Runs 1, 2, and 3 were used to adjust the 
mechanics of the system and run 9 was aborted because of a leak. Runs 7 and 8 are very similar in $R$ and flow rate, as are runs 11 and 12 . The differences between members of these pairs indicate the reproductibility of the experimental system.

In the second theoretical model, tested in run No. 14, there is continuous "perfect mixing" during production flow. Under these conditions, the fluid leaving the chimney immediately begins to show the effect of the fluid flowing into the chimney from outside. Theoretically, the chimney will never be purged completely because there is always some of the original chimney material present; the concentration of original material gradually approaches zero, but is equal to zero only at infinite time. The results shown in Fig. 14 are very close to the theoretical model.

Run 13 (see Fig. 13) was performed without glass beads and without stirring in the center volume in order to determine the maximum amount of diffusion and mixing which was caused by the acid concentration gradient. It can be observed that the results resemble runs 11 and 12 closely, so the mixing induced by acid gradients (while obviously present) probably is not perturbing results grossly.

In summary, the results indicate the experimental data falls between the two theoretical extremes: (1) conditions resemble simple fluid-displacement flow at the start and, (2) at late times, diffusion and dispersion result in a condition more nearly related to "perfect mixing." The test in which stirring and constant mixing were employed (run 14), closely corresponds to the theoretical curve and is probably indicative of the general accuracy of the test method.

\section{Conclusions}

It can be concluded: (1) in the absence of mechanical mixing, the fluid in the more permeable central column was purged more nearly in accordance with the "displacement" theory, (2) the experimental setup was not perfect, in that flow through the fine sand could be variable over the surface of the cylinder, (3) it is likely that production of radioactive gas from nuclear chimneys in gas-bearing rock will be influenced by several processes such as: (a) convective mixing leading to more nearly exponential decay of effluent concentrations; (b) nonuniform production from the chimney walls; and (c) intermittent rates of production required by other constraints. All of these factors will tend to make the real field observations fall between the extremes presented by the two theoretical models.

The tests are sufficiently convincing to warrant purge tests of nuclear chimneys when it becomes desirable that all the radioactive gases be reduced 100 -fold or more in concentration with minimum gas flaring.

In order to minimize this total amount of gas flared during purging, the purging rate (flow-rate) should be as high as possible to minimize thermal convective mixing and the purging should proceed uninterruptedly. Any interruption will allow mixing to recontaminate those areas already cleaned by incoming gases. It is unfortunate that 
field tests such as those conducted on Project Gasbuggy prior to the fall of 1968 were interrupted and provided almost no new data. From the $\mathrm{Kr}^{85}$ concentration reported by Smith and Momyer ${ }^{5}$ it can be concluded that initially the concentrations were constant, consistent with the displacement model, but that convective mixing was occurring at such a degree that after shut-in of several days duration, the contaminant would be uniformly remixed.

\section{References}

1. G. H. Higgins and H. C. Rodean, Some Calculations for Effecting Oilfield Stimulation by Nuclear Means, Lawrence Radiation Laboratory, Livermore, Rept. UCRL-14311 (1965).

2. M. Muskat, "The Flow of Homogeneous Fluids through Porous Media" (McGrawHill Book Co., Inc., New York, 1937).

3. M. Muskat, "Potential Distribution in Large Cylindrical Discs with Partially Penetrating Electrodes, Physics 2 , 329-364 (1932).

4. H. B. Dwight, "Tables of Integrals and Other Mathematical Data" (The Macmillan Company, New York, 1957), 3 ed., p. 134.

5. C. F. Smith and F. F. Momyer, Gas Quality Investigation Program Status Report for Project Gasbuggy, Law rence Radiation Laboratory, Livermore, Rept.

UCRL-71314, Rev. I, (1968). 


\section{Distribution}

LRL Internal Distribution

Michael M. May

D. Sewell

R. E. Batzel

H. L. Reynolds

J. W. Gofman

R. Herbst

A. C. Haussmann

C. A. McDonald

J. W. Rosengren

E. Teller

D. Dorn

G. C. Werth

J. E. Carothers

G. D. Dorough

F. S. Eby

E. H. Fleming

W. B. Harford

G. H. Higgins

F. Holzer

D. D. Rabb

5

H. C. Rodean

J. S. Kahn

J. S. Kane

J. B. Knox

B. C. Hughes

T. Perlman

P. H. Moulthrop

M. D. Nordyke

B. Rubin

P. C. Stevenson

H. A. Tewes

C. E. Williams/P. E. Coyle

J. T. Cherry

L. Crooks/E. Harp, Mercury

TID Berkeley

TID File 


\section{External Distribution}

J. S. Kelly

Division of Nuclear Explosives

Washington, D. C.

J. E. Reeves

Nevada Operations Office

Las Vegas, Nevada

E. C. Shute

J. F. Philip

San Francisco Operations Office

Berkeley, California

TID-4500 Distribution, UC-35, Nuclear Explosions-Peaceful Applications

A. Makes any warranty or representation, expressed or implied, with respect to the accuracy, comaletentess o: usefulness of the infomation contained in this report. of that the use of any information, appatatus, melthod, of process disclosed in th:s report may not infringe privately owned rights; or

B. Assumes any liabilities with respect to the use of, or for damages resulting from the use of any information. apparatus, method or process disclosed in this report

As used in the above, "person acting on behalt of the Commission" ancludes any employee of contractor of the Commission, of employee of such contractor, to the extent that such employee or contlactor of the Cominission, or employee of sich contractor piepares, disseminates, or provides access to. any information pursuant to his employment or contlact with the Commission. or his employment with such contractor.

Printed in USA. A vailable from the Clearinghouse for Federal Scientific and Technical Information, National Bureau of Standards, U.S. Department of Commerce, Springfield, Virginia 22151 Price: Printed Copy $\$ 3.00$; Microfiche $\$ 0.65$. 